\title{
Stability Analysis of variation Span and Turning Angle against Width in suspension bridge
}

\author{
Bambang Supriyadi, Suprapto Siswosukarto, Imanuel Elvis S. Hadjoh
}

\begin{abstract}
One of the critical issues for a long suspension bridge is the vibration induced by wind. The excessive vibration on long suspension bridge owing to bridge flexibility may cause the bridge's aerodynamic instability and vehicle accidents. Therefore, in the present study, the optimum ratio for the span and turning angle to bridge width was investigated. The analysis was carried out on bridge with total span of $470 \mathrm{~m}$, main span $270 \mathrm{~m}$ and side span $100 \mathrm{~m}$, using variations of bridges width ranging from $9 \mathrm{~m}$ to $22 \mathrm{~m}$. SAP2000 program was used to analyze the stability behavior of the suspension bridge under wind load at speed of $35 \mathrm{~m} / \mathrm{s}$. The results of analysis shows that the optimum ratio of span to width bridge is $0.034 \mathrm{~L}$ or $\mathrm{L}=29.375 \mathrm{~b}$. When the turning angle was taken into consideration in the analysis, it will result in increasing the bridge's stability, decreasing natural frequency of the structure and increasing stresses on the cables. Further, it was also found that the deflection and the internal forces on the girder meet the specified limits by AASHTO and AISC standard specification.
\end{abstract}

Keywords - suspension bridge, wind, vibration, stability analysis, turning angle

\section{Introduction}

Suspension bridges is one of famous type of bridge that suitable for super long and a larger span bridges which less material consumption [1-3]. As bridge's span get larger and longer than any other type of bridge, it results in high susceptibility to dynamic load, wind-induced vibrations and low bending-torsional frequencies $[4,5]$.

On 7 November 1940, the old Taccoma Narrow bridge collapsed due to the wind that cause the bridge deck to wobble violently side to side, twisted and then fell down. Since the collapse of the old Taccoma Narrow bridge, the aerodynamic instability of long-span bridge modern design become the most important issues that has received special attention and various studies have been carried out by researchers [6-9].

Bambang Supriyadi

Civil Engineering and Environment Department, Universitas Gadjah Mada, Yogyakarta, Indonesia,

Suprapto Siswosukarto

Civil Engineering and Environment Department, Universitas Gadjah Mada, Yogyakarta, Indonesia,

\section{Imanuel Elvis S. Hadjoh}

Graduate Student, Civil Engineering and Environment Department, Universitas Gadjah Mada, Yogyakarta, Indonesia

Made Suangga and Andi Wiryana [9] analyzed the same bridge model of Old Tacoma Narrows Bridge using the distance between pylons of 2,800 ft ( $853.44 \mathrm{~m})$ and height of $425 \mathrm{ft}(129.54 \mathrm{~m})$, and also using girder of steel plate. The main problem of bridge with plate girder is the bridge's flexibility that becomes very high for both vertical and torsional directions. This is due to the thickness of the high girder and the bridge's width compared to bridge's span. The analysis result shows that the bridge underwent choppy motion until finally collapsed on November 7, 1940 due to wind at speed of $42 \mathrm{mph}(18,8 \mathrm{~m} / \mathrm{s})$. From the flutter analysis in 3 dimensions of the Old Naruto Taccoma bridge it was found that the phenomenon of flutter collapse occurred at a wind speed of $14 \mathrm{~m} / \mathrm{s}$. So this analysis concluded that the cause of the bridge to collapse was due to the influence of dynamic wind. While based on the field information it was found that the wind speed at the time the bridge collapsed was $42 \mathrm{mph}$ or about $18.8 \mathrm{~m} / \mathrm{s}[8,9]$.

Jewel Sarker1 and Tanvir Manzur [3], in Optimum Dimensions of Suspension Bridges Considering Natural Period, studied the effect of different structural element on the natural period of suspension bridge. The study analyzed the natural periods of bridges by modal analysis of central span lengths ranging from $600 \mathrm{~m}$ to $1400 \mathrm{~m}$ using SAP2000 software. The study revealed that the increase in the central span was followed by the decrease in the lateral stiffness of the suspension bridges, the lateral vibration becomes significant when the central span is above $1000 \mathrm{~m}$. The study also concluded that the relationship between tentative optimum deck depth, optimum tower height and central span of suspension bridge has significant effect on the natural period. This relationship can be used to obtain the tentative optimum dimensions of a suspension bridge with central span between $600 \mathrm{~m}$ to $1400 \mathrm{~m}$.

Many researchers studied about the flutter analysis of the suspension bridge due to the effect of bridge-deck characteristics but there are lack of study investigating the influence of ratio between span, turning angle and width of bridge to the dynamic behavior of long span bridge. Therefore, the purpose of this research is to study the effect of ratio between span, turning angle and the bridge width on the bridge structural stability.

In this study SAP2000 software was used to model and analyses the stability of suspension bridge's structure that withstands static and dynamic loads including the wind load acting on the bridge deck at the speed of $35 \mathrm{~m} / \mathrm{s}$. Moreover, this study is also intended to optimize the ratio between the span, turning angle and bridge width for maximum stability. 


\section{Research Method}

\section{A. Initial dimension}

In this research, stability analysis was carried out on Kutai Kartanegara bridge that have main bridge span of $270 \mathrm{~m}, 100$ $\mathrm{m}$ side span, $9 \mathrm{~m}$ of width with 2 lane and $1 \mathrm{~m}$ sidewalk. The width of the bridge was varied from 9 to $22 \mathrm{~m}$ for KutaiKartanegara bridge and 9 to $22 \mathrm{~m}$ for the suspension bridges using Stiffening Truss. In order to study the behavior of bridge stability due to the ratio of bridge's width and span length to wind load, then the bridge width was increased every $1 \mathrm{~m}$. Two pylon was placed at a distance of $270 \mathrm{~m}$. It was made with shape of concrete portal height of $7.725 \mathrm{~m}$ at the bottom and a steel portal height of $38 \mathrm{~m}$ at the top and was connected by baseplate and anchor. The illustration of the technical design of the model is presented in Fig.1, Fig.2,and Fig,3.

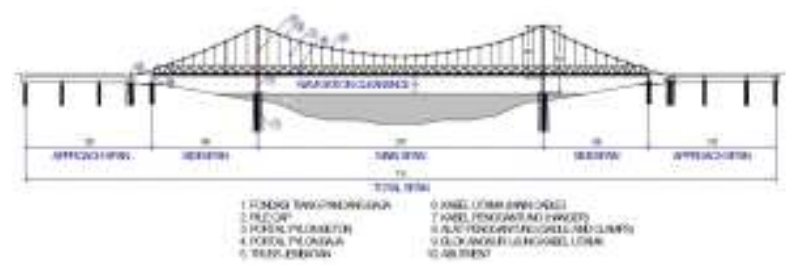

Figure.1. Technical design of the bridge model.

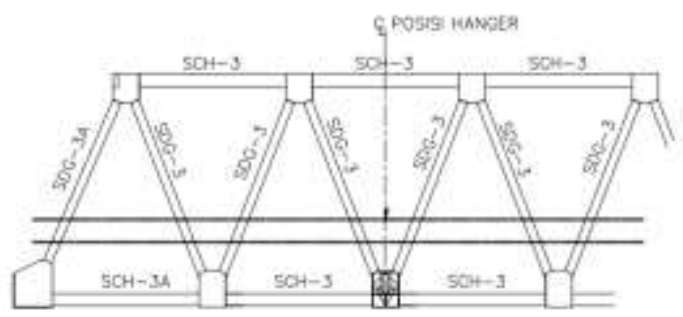

Figure.2. Ilustration of truss of the bridge model

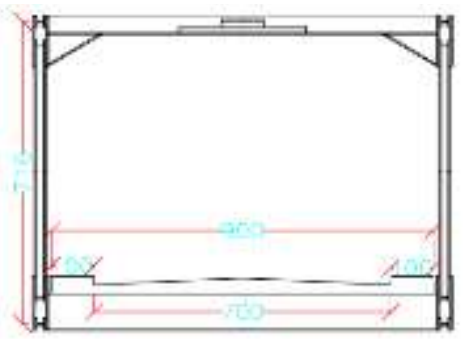

Figure.3. The front view of the bridge model.

\section{B. Structural modelling}

The analysis of structural models were carried out in tree dimension using SAP2000 software (Fig.4) to evaluate the bridge stability under wind load at speed of $35 \mathrm{~m} / \mathrm{s}$ and taking into account all structural components of the upper structure of the bridge.
The materials specifications used for structural modeling in SAP 2000 programe are as follows:

a) Concrete for the main structure (pylon) using high quality concrete, $f^{\prime}{ }_{c}=40 \mathrm{MPa}$.

b) Steel for frame with yield strength $\left(f_{y}\right)$ of $490 \mathrm{MPa}$.

c) The suspension cable type is Low Relaxation Strand fabricated by VSL with specification according to ASTM A-506 by $f_{y}=1.034 \mathrm{MPa}$ and $F_{u}=1.516 \mathrm{MPa}$.

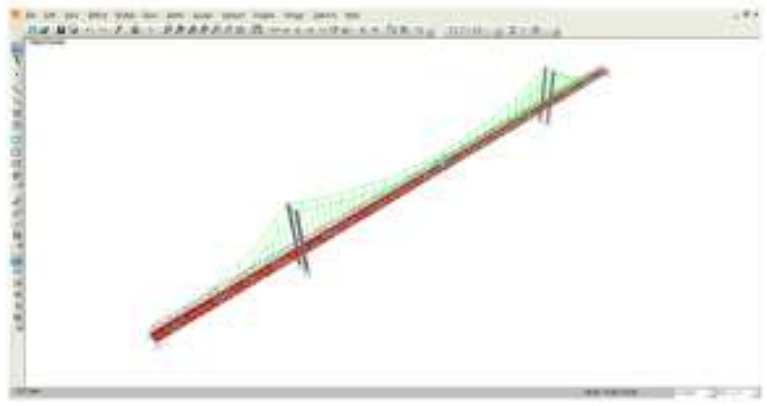

Figure.4. The tree dimension (3D) structural analysis of the bridge model in SAP2000 programe.

\section{Basic design}

In analyzing the stability of overall structure, the load from the bridge floor is supported jointly by the cable and the staked girders based on the principle of deflection compatibility (combination between cable and deck to support deflection).

\section{A. Stability}

To calculate the stability analysis of the 3D model of bridge using SAP200 software is [8,9]:

$[\mathrm{M}]\{\mathrm{u}\}+[\mathrm{K}]\{\mathrm{u}\}=\{0\}$

Solution of the above differential equation is:

$\left\{\mathbf{u}_{(0)}\right\}=\{\mathrm{A}\} \sin (\omega \mathrm{t}+\alpha)$, Or

$\{\mathrm{u}\}=-\{\mathrm{A}\} \omega^{2} \sin (\omega \mathrm{t}+\alpha)$

Where :

$\{\mathrm{A}\}=$ Matrix of deformation characteristics

$[\mathrm{K}]=$ Structure stiffness matrix

$[\mathrm{M}]=$ Mass matrix

$\omega \quad=$ Angular frequency

$\alpha=$ Phase matrix of deformation matrix

\section{B. Fundamental bending frequencies}

The determination of the fundamental bending frequency was carried using an approximation value according to the equation [10] :

$$
F_{b}=\frac{1.1}{2 \pi}\left[\frac{g}{v m a k s}\right]^{\frac{1}{2}}
$$

Where :

$V_{\text {maks }}=$ Maximum deflection due to its own weight

$g \quad=$ Acceleration of gravity 


\section{Aerodynamic force modelling}

Flutter phenomenon is caused by the presence of Aerodynamic force that occurs due to the interaction between wind turbulence and vibration from the structure. Therefore, defining the magnitude of the Aerodynamic force is an important step to evaluate the aerodynamic stability of the Bridge. The equation proposed by Bleich [8] was used to determine the aerodynamic force modeling:

$$
\begin{gathered}
L=-\frac{1}{2} \rho U^{2} b(2 \pi)\left\{\frac{b}{U} \alpha+\frac{b}{U^{2}} h-\frac{b^{2} a}{U^{2}} \alpha\right. \\
\left.+2 C_{(k)}\left[\alpha+\frac{h}{U}+\left(\frac{1}{2}-\alpha\right) \frac{b}{U} \alpha\right]\right\} \\
M=-\frac{1}{2} \rho U^{2} b^{2}(2 \pi)\left\{\frac{b}{U}\left(\frac{1}{2}-a\right) \alpha+\frac{b}{U^{2}}\left(\frac{1}{8}+a^{2}\right) \alpha\right. \\
-\frac{b^{2} a}{U^{2}} h \\
\left.+2\left(\frac{1}{2}+a\right) C_{(k)}\left[\alpha+\frac{h}{u}+\left(\frac{1}{2}-\alpha\right) \frac{b}{U} \alpha\right]\right\}
\end{gathered}
$$

Where :

$b$ : half the bridge width

$a$ : the distance between the center of the deck to the center of the shear

$h$ : vertical displacement

$\alpha$ : torque

$U$ : wind speed

$C$ : damping matrix

\section{Pylon}

The height of pylon is determine by cable, system type, aesthetic comparison of the height and span length. The shape of the pylon can be portal, multistory or diagonally braced frame. According to Poldony and Scalm [1], the proportion of the longest span to the highest pylon should be between 0.19 0.25 . The height $(H)$ of pylon is the function of panel's length $(L)$ and can be written :

$$
\frac{H}{L}=\frac{1,4 a}{n+1,3 a}
$$

\section{E. Compatibility deflection of cables and truss}

Cable and deck on suspension bridge with stiffening truss support the load in accordance with the principle of deflection compatibility where the deflection of the bridge is the result of changes in shape and the increase of cable length and deck deflection.

The relationship between the cables and the stiffness of the truss is expressed in the form of $\mathrm{N}$, as follows:
Where :

$$
N-\frac{8}{5}-\frac{3 E I}{A f^{2} E_{s}}\left(1+8 n^{2}\right)
$$

$$
\begin{aligned}
& E=\text { the elastic modulus of the deck material } \\
& I=\text { moment of inertia cross section of deck material } \\
& A=\text { the main cross-sectional area of the cable } \\
& E_{s}=\text { main cable elastic modulus }
\end{aligned}
$$

Horizontal component or horizontal voltage cable:

$$
H_{\text {max }}-\frac{1}{5 N_{n}} P l
$$

The deflection on the deck is :

$$
d=\frac{5 P l^{4}}{384 E I}\left(1-\frac{8}{5 N}\right)
$$

\section{F. Flutter effect}

The flutter phenomenon of the bridge girder using Reynolds (Re) and Strouhal (S) numbers proposed by von Karman [10], can be defined by the following equation:

$$
\begin{gathered}
R E=\frac{V E}{v} \\
S=\frac{f^{h}}{v}
\end{gathered}
$$

Where :

$V=$ wind speed

$B=$ the width of the deck

$v=$ kinematic air viscosity $\left(\approx 0.15 \mathrm{~cm}^{2} / \mathrm{s}\right)$

$f=$ frequency of vortices (vortices)

$h=$ deck depth.

The flutter frequency depends on the wind velocity $V$. Stouhal number (S) has an average value of 0.2 for a cylinder with a diameter of $h$ and $0.1-0.2$ for a bridge deck with a depth of $h$ ( 0.1 if wind only flows from one side).

\section{Result and discussion}

The SAP2000 analysis considered six load combinations according to Indonesian standards, which consists of combination of dead load $(D L)$, live load $(L L)$, wind load $(W)$, earthquake load $(E Q)$, and moving load load $(M L)$. The SAP2000 analysis was carried out to investigate the internal forces that occur in the suspension bridge structure.

\section{A. Suspension cable stress}

Figure 5 shows the analysis result of the axial force of cables. From the Fig.5, it is shown that axial force was bigger as the width of the bridge get wider. This is due to the fact that the wider bridge have a significant effect in resulting heavier self-weight and service load of the bridge [8]. 
Proc. of the Fifth Intl. Conf. Advances in Civil, Structural and Mechanical Engineering - CSM 2017

Copyright (C) Institute of Research Engineers and Doctors, USA .All rights reserved.

ISBN: 978-1-63248-132-0 doi: 10.15224/ 978-1-63248-132-0-34

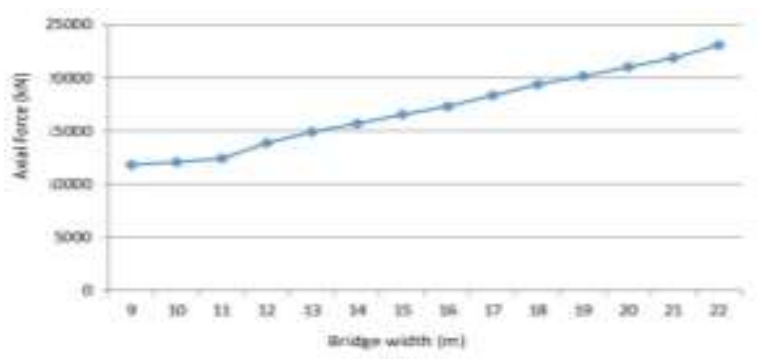

Figure.5. Axial forces in cables $(\mathrm{kN})$.

\section{B. Girder}

The girder was modeled as a 3D frame element and was design as a box girder where the cable was placed at the joint between the elongated and transverse girder elements. The girth's width was set according to variation of bridge width ranging from $9 \mathrm{~m}$ to $22 \mathrm{~m}$ with width increment of $1 \mathrm{~m}$ for analysis purposes. The live loads was modeled to act along the length of the girder rail, while the load on the rods was modeled as a point load on each joint between cable and girder. Figure 6 shows results of internal forces of the girder.

From Fig.6, it can be seen that the increase in bridge width will result in increase of internal forces on the girder. This is due to the increase in load acting on the structure as well as the addition of number of lines.

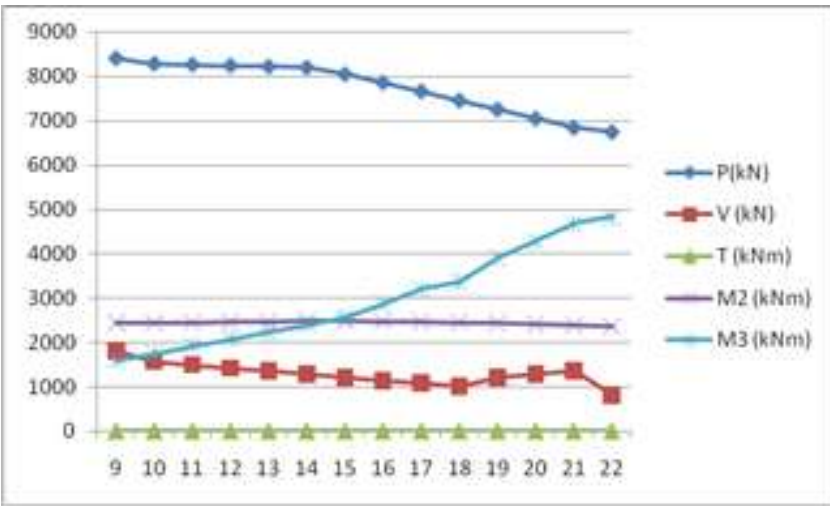

Figure.6. Internal forces of the girder.

\section{Pylon deformation}

Figure 7 show the results analysis of deformation of the tower of bridge. It indicates that the increase in bridge width will also results in bigger deformation of tower. The increase in deformation of bridge tower is due to an increase in load acting on the bridge deck.

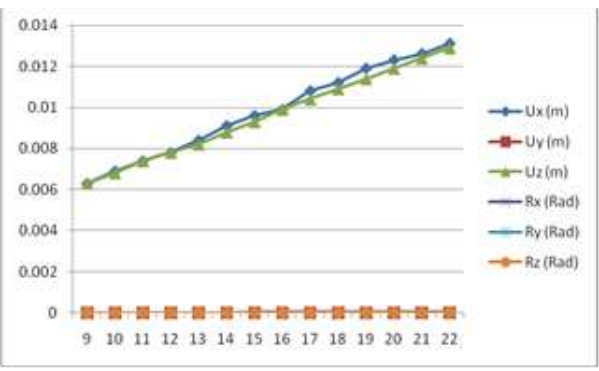

Figure.7. Deformation of tower

\section{Bridge deck deformation}

The deformation under consideration is due to dead load, live load, earthquake load, wind load, and moving load. The maximum deflection in the middle span caused by combination of loading is considered. The mains span is deformed in the direction of the $\mathrm{z}$ axis (-), while the side span is deformed in the direction of the $\mathrm{z}$ axis $(+)$.

Based on the SAP 2000 analysis results, it can be obtained that the deformation on the bridge deck is within the limits allowed by AASHTO and AISC, as calculated as follows:

AASHTO:

$$
\delta_{\text {maks }}=\frac{L}{800}=\frac{470}{800}=0.5785
$$

AISC:

$$
\delta_{\text {maks }}=\frac{L}{360}=\frac{470}{360}=1.305
$$

\section{E. The relationship between natural frequency, cable stress and deflection}

To obtain the ratio of bridge width to bridge length, it is necessary to compare the natural frequency, cable stress and deflection such that the optimal width can be obtained. To do so, the result analysis of natural frequency, cable stress and deflection are scaled down and plotted in the same graph. Optimum bridge width can be obtained from the intersection between the figures. Figure 8 shows the relationship between natural frequency, cable stress and deflection.

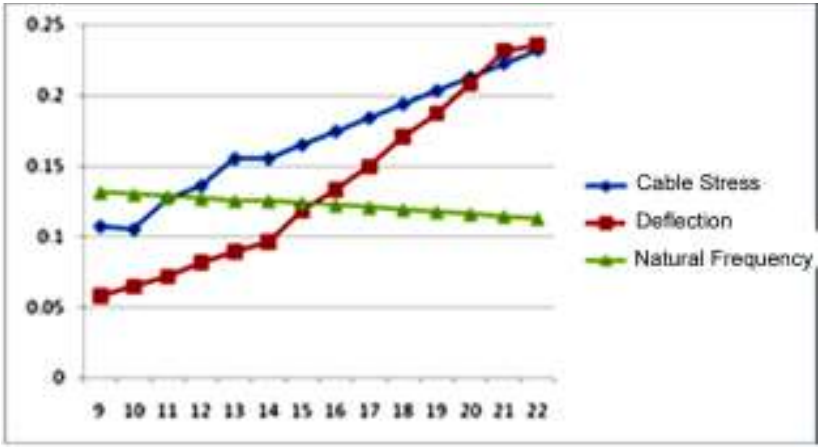

Figure.8. The relationship between natural frequency, cable stress and deflection

Figure 8 shows the intersection between the natural frequency and cable stress of the bridge is on the bridge width of $15 \mathrm{~m}$ and the intersection between deflection and natural frequency is on the bridge width of $18 \mathrm{~m}$. It could be conclude that the optimum width for suspension bridge with $470 \mathrm{~m}$ span is $15 \mathrm{~m}$. Hence,

$$
\frac{b}{L}=\frac{15}{470}=b=0.032 L \text { or } L=31.333 b
$$




\section{F. The relationship between natural frequency, cable stress, deflection and Rotation Angle}

From the SAP 2000 analysis, it was obtained that the optimum width for suspension bridge with bridge span of 470 $\mathrm{m}$ is $15 \mathrm{~m}$. The optimum ratio of the suspension bridge span and width were obtained by plotting the results analysis of cable stress, deflection, natural frequency and rotation angle into one graph, as depicted in Figure 9. Based on the deflection on one side of the deck, the value of the rotation angle that exists on the deck can be determined. Then, the ratio of bridge width and bridge span is obtained.

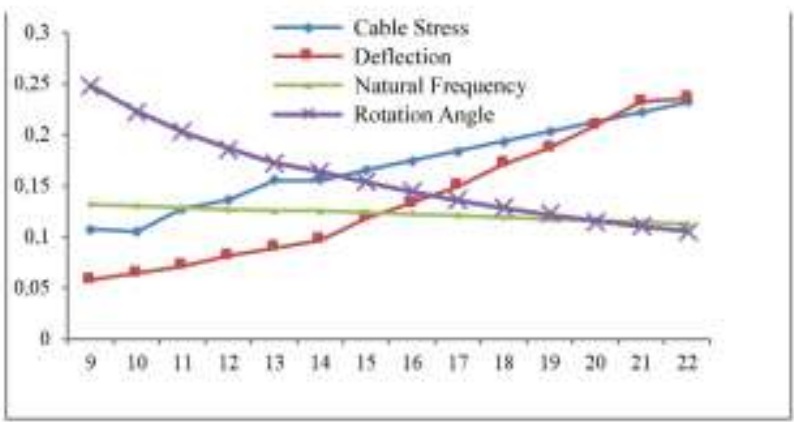

Figure.9. The relationship between natural frequency, cable stress, deflection and Rotation Angle into one graph.

From Figure 9, it can be seen that when the effect of rotation angle in the suspension bridge is taken into account, for suspension bridge span of $470 \mathrm{~m}$, the ratio of bridge width to span changes from 15 to $19.5245 \mathrm{~m}$ at the deflection value of 0.1167 . Hence, the ratio of bridge width to span can be obtained as follows;

$$
\frac{b}{L}=\frac{19.524}{470}=b=0.04154 L \text { or } L=24.0729 b
$$

\section{v. Conclusion}

From the results stability analysis for suspension bridge with bridge width variation of $9 \mathrm{~m}$ to $22 \mathrm{~m}$, it can be concluded several results as follows:

1. The optimum ratio of width and span especially for suspension bridge was obtained (around $0.034 \mathrm{~L}$ or $\mathrm{L}=29.375 b$ ).

2. The addition of rotation angle into consideration in the analysis will result in decreasing the natural frequency of the structure, and increasing the cable stress as well as deflection and forces of the girder

3. Based on the results of analysis, it is shown that the deformation occurring on the bridge deck is still within the limits allowed by AASHTO and AISC, as follows,

AASHTO :

$$
\delta_{\text {maks }}=\frac{L}{800}=\frac{470}{800}=0.5785
$$

AISC :

$$
\delta_{\text {maks }}=\frac{L}{360}=\frac{470}{360}=1.305
$$

\section{References}

[1] bridges : The Tacoma Narrows Bridge case. Commun Nonlinear Sci Numer Simulation, 42, 324 - 357.

Scalm, P. a. J. B. (1976). Cable Stayed Bridges Theory and Design. New York: John Wiley \& Sons Inc.

Walther, R. (1988). Cable Stayed Bridges: Thomas Telford.

Wiryana, M. S. a. A. (2008). Flutter analysis of old tacoma narrow bridge. Jurnal Dinamika Teknik Sipil, 11.

G. Diana , Y. Y., A.Larsen , D.Rocchi , S.Giappino , T.Argentini , A.Pagani , M. Villani , C.Somaschini , M.Portentoso (2013). Construction stages of the long span suspension Izmit Bay Bridge: Wind tunnel test assessment. J. WindEng.Ind.Aerodyn, 123, 300310.

Jewel Sarker, T. M. (2013). Optimum Dimensions of Suspension Bridges Considering Natural Period. IOSR Journal of Mechanical and Civil Engineering, 6(4), 67-76.

Firoz Abbasi, S. P. (2015). A Review and Analysis of Suspension Bridge Structures. International Journal of Science and Research, 6, 1050 -1052.

Bambang Supriyadi1, S. S., Algazt A. Masagala, Imanuel Elvis S., \& Hadjoh. (2016). The Effect of Deck Width Addition Toward Stability of Cable Stayed Bridge: Case Study of Siak Sri Indrapura Bridge, Riau. Paper presented at the MATEC Web of Conferences. Hiroshi Katsuchi, H. Y., Mayuko Nishio, Yoko Okazaki. (2016). Improvement of aerodynamic stability of suspension bridges with H-shaped simplified stiffening girder. Front. Struct. Civ. Eng., $10(1)$.

Michael Styrk Andersen, J. J., Anders Brandt, Svend Ole Hansen. (2016). Aerodynamic Stability Of Long Span Suspension Bridges With Low Torsional Natural Frequencies. Engineering Structures, 120, 82-91

Shrestha, J. K. (2016). Effect of Modification of Deck Properties on Suspension Bridges Journal of the Institute of Engineering, 12(1), 39-50

Gianni Arioli , F. G. (2017). Torsional instability in suspension 